Eur $\mathrm{J}$ Clin Chem Clin Biochem

1995; 33:343-349

(C) 1995 Walter de Gruyter \& Co.

Berlin · New York

\title{
An Improved Method for Determination of Thiocyanate in Plasma and Urine ${ }^{1}$ )
}

\author{
By Per Lundquist ${ }^{1,2}$, Bertil Kågedal $^{1}$ and Lennart Nilsson ${ }^{1}$ \\ 1 Department of Clinical Chemistry, University Hospital, Linköping, Sweden \\ 2 SKL - National Laboratory of Forensic Sciences, Linköping, Sweden
}

(Received September 20, 1994/March 20, 1995)

Summary: An improved spectrophotometric method is described for the determination of thiocyanate in plasma and urine. Thiocyanate is adsorbed on a weak anion-exchange resin with strong affinity for chaotropic ions, and eluted with perchlorate. Thiocyanate is then chlorinated by hypochlorite and quantified according to the König (J Prakt Chem 1904; 69:105-37) reaction by use of isonicotinic acid and 1,3-dimethyl-barbituric acid. The method affords a simple, rapid and sensitive assay for thiocyanate and has a detection limit of $0.93 \mu \mathrm{mol} / 1$. At thiocyanate concentrations of 107.1 and $167.4 \mu \mathrm{mol} / 1$ in plasma and urine the within-day CVs were $0.69 \%$ and $1.1 \%$ respectively, and the total imprecision measured for a period of 65 days was $0.98 \%$. Analytical recoveries were quantitative both with urine and plasma samples.

\section{Introduction}

Natural exposure of cyanide during evolution has resulted in complex mechanisms for its detoxication in man. In the major pathway, cyanide is metabolized to thiocyanate after reacting with a sulfur donor, such as thiosulfate. This reaction is catalyzed by the enzyme rhodanase (EC 2.8.1.1) $)^{2}$ ). Determination of thiocyanate in serum and urine is therefore of great interest in monitoring cyanide exposure from tobacco smoke (1), fire smoke (2) and from ingested cyanogenic glucosides (3). Intake of thiocyanogenic glucosides (glucosinolates) present in cabbage and vegetables of the Brassica family and mustard (4), and intake of thiocyanate-containing food such as milk and cheese elevate the thiocyanate concentration in body fluids.

\footnotetext{
1) Funding organisations:

The Swedish Medical Research Council (Project No. B95-13X11211-01A),

The Swedish Tobacco Company (Svenska Tobaks AB), Project No. 9414 ,

The Swedish Cancer Society (Project 2357-B94-09XCC),

The Swedish Society of Medicine,

The County Council of Östergötland and

The Lions Foundation for Medical Research

2) Enzyme:

Rhodanase (thiosulfate sulfurtransferase) (EC 2.8.1.1)
}

Thiocyanate present in blood is partly bound to plasma albumin (5). When plasma concentration of thiocyanate exceed $250 \mu \mathrm{mol} / 1$, thiocyanate is excreted into the urine as the reabsorption in the tubules becomes saturated $(6$, 7). The estimated plasma elimination half-life of thiocyanate is 2.7 days in healthy subjects (8).

Several methods for determination of thiocyanate have been described based on the colorimetric method developed by König in 1904 (9). These methods constitute multi-step reactions where thiocyanate is first halogenated to cyanogen chloride or cyanogen bromide. In the König method (9) the cyanogen halide then reacts with pyridine yielding glutaconic aldehyde, and this compound then reacts with a primary amine producing a dye which is quantified spectrophotometrically. After the first description of the method several modifications have appeared (10-26), but unfortunately all of them involve handling of unpleasant or toxic compounds, e.g. bromine, arsenite, benzidine, pyridine and 1-phenyl-3methyl-5-pyrazolone.

Isonicotinic acid is unnoxious and releases no unpleasant vapour. This reagent was first used in the König reaction by Ishii et al. (21) in a modification where pyrazolone dissolved in dimethylformamide-water was used in- 
stead of barbituric acid. Nagashima (23) used sodium isonicotinate together with barbiturate and obtained a stable reagent. Earlier 1,3-dimethylbarbituric acid was used in combination with pyridine (24), and recently the combined use of isonicotinic acid and 1,3-dimethylbarbituric acid was introduced for determination of cyanide and thiocyanate in water by Meeussen et al. (26). This combination was also utilized for analysis of cyanogens in cassava (25). Although this is an attractive reagent combination, it has not earlier been used for analysis of thiocyanate in plasma and urine.

The aim of the present investigation was therefore to optimize the König reaction for analysis of thiocyanate in plasma and urine with isonicotinic acid and 1,3-dimethylbarbituric acid as substitutes for pyridine and barbituric acid. The reaction mechanism is shown in figure<smiles>Cc1cc(C(=O)O)cc[n+]1C#N</smiles>

2

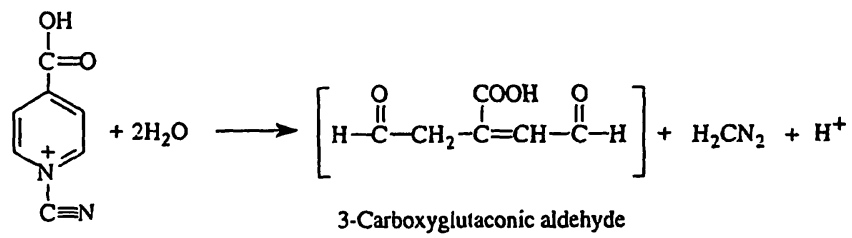

3

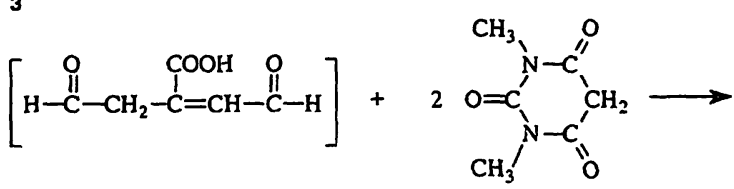

1,3-Dimethylbarbituric acid<smiles>CN1C(=O)C(=CCC(=CC2C(=O)N(C)C(=O)N(C)C2=O)C(=O)O)C(=O)N(C)C1=O</smiles><smiles>CN1C(=O)C(=CC=C(C=Cc2c(O)n(C)c(=O)n(C)c2=O)C(=O)O)C(=O)N(C)C1=O</smiles>

1,5-Bis(pyrimidene-1',3'-dimethyl-2',4',6'-trione-5'-ylidenc)-3-carboxy-2-pentene

Fig. 1 Reaction scheme for determination of thiocyanate and cyanide

After cyanogen chloride has been formed from the reaction between thiocyanate and hypochlorite it reacts with isonicotinic acid to produce 3-carboxyglutaconic aldehyde (intermediate). Condensation of the aldehyde with two molecules of 1,3-dimethylbarbituric acid finally gives the dye.
1. The clean-up and chlorinating of the purified sample with sodium hypochlorite is an updated modification of our earlier method.

\section{Materials and Methods}

Materials

$\cdot 1$

\section{Ion exchanger}

Amberlyst A-21, 20-50 mesh was purchased from Sigma Chemical Co. (St. Louis, MO). The resin was dried in an oven at $\leq 100^{\circ} \mathrm{C}$ for 24 hours and thereafter ground in a laboratory mill (Cemotec 1090 Sample Mill, Tecator AB, Höganäs, Sweden). A particle size of $0.1-0.3 \mathrm{~mm}$ was obtained by sieving the dry resin. Then the resin was slurried into 2 volumes of de-ionized water and allowed to sediment for $5-10$ minutes. The supernatant containing fine particles was decanted to ensure an optimal column flow rate, and the procedure was repeated 3-4 times. The resin was transferred to a suitable column, washed with 3 volumes of hydrochloric acid, $1 \mathrm{~mol} / \mathrm{l}$, followed by de-ionized water to neutral $\mathrm{pH}$ ( $\mathrm{pH}$-indicator paper). Then the resin was washed with 10 volumes of sodium hydroxide, $1 \mathrm{~mol} / \mathrm{h}$, followed by de-ionized water to neutral $\mathrm{pH}$. The resin could be stored for at least one year at $+4^{\circ} \mathrm{C}$. For preparing 1-ml columns of the resin, 0.7 (i. d.) $\times 2.5 \mathrm{~cm}$, we used the "Econo-Columns", 0.7 (i. d.), $\times 4.0 \mathrm{~cm}$, from Bio-Rad Laboratories. Alternatively, the cheaper Poly-Prep Columns, 0.8 $\times 4.0 \mathrm{~cm}$ (Bio-Rad Labs.) could be used.

\section{Reagents}

All reagents were prepared from analytical grade chemicals (unless otherwise specified) and were dissolved in de-ionized water.

Potassium thiocyanate and sodium perchlorate monohydrate were obtained from E. Merck (Darmstadt, Germany). Isonicotinic acid (purum) and 1,3-dimethylbarbituric acid (puriss) were obtained from Fluka Chemie AG, (Buchs, Switzerland). Sodium hypochlorite, $0.5 \mathrm{~mol} / 1$ dissolved in $\mathrm{NaOH} 0.1 \mathrm{~mol} / 1$ (reagent no. 23039) was obtained from BDH Chemicals (Poole, England) and was diluted 10 -fold to a final concentration of $50 \mathrm{mmol} / \mathrm{l}$. This reagent is stable for at least one month at $+4^{\circ} \mathrm{C}$.

Potassium thiocyanate working standards, 20, 50, 100, 200, and $300 \mu \mathrm{mol} / \mathrm{l}$, were prepared daily from a $100.0 \mathrm{mmol} / \mathrm{l}$ stock standard solution. The colour reagent was prepared by dissolving $0.925 \mathrm{~g}$ of $\mathrm{NaOH}$ in $50 \mathrm{ml}$ water. Then $1.75 \mathrm{~g} \mathrm{1,3-dimethylbarbi-}$ turic acid and $1.43 \mathrm{~g}$ isonicotinic acid were added to the alkaline solution. This reagent is stable for at least 4 months at $+4{ }^{\circ} \mathrm{C}$. As a blank we used de-ionized water.

\section{Apparatus}

During the optimization of the method we used a Shimadzu Model UV-2101 PC UV-VIS Scanning spectrophotometer (Şhimadzu Corporation, Analytical Instruments, Kyoto, Japan). Otherwise, we used a Zeiss PM 2K spectrophotometer.

\section{Procedure}

A $0.5-\mathrm{ml}$ aliquot of blank, working standards, plasmà or urine was diluted with $5.0 \mathrm{ml}$ of $\mathrm{NaOH}, 1.0 \mathrm{~mol} / \mathrm{l}$, and applied to a $2.5 \times 0.7$ $\mathrm{cm}$ column of Amberlyst A-21. The column was washed three times with 5-ml portions of water, and then thiocyanate was eluted by $8.0 \mathrm{ml}$ of $\mathrm{NaClO}_{4}, 1 \mathrm{~mol} / \mathrm{h}$. To a $4.0-\mathrm{ml}$ aliquiot of the eluate we added $0.2 \mathrm{ml}$ of acetic acid, $0.35 \mathrm{~mol} / \mathrm{l}$, and mixed on a Vortex mixer. The chlorinating reaction was then performed by adding 0.1 $\mathrm{ml}$ of sodium hypochlorite, $50 \mathrm{mmol} / \mathrm{l}$, and the sample was again mixed. Then within $2 \mathrm{~min}, 0.6 \mathrm{ml}$ of the colour reagent was added. 
After 10 min the absorbance was read at $607 \mathrm{~nm}$ and the amount of thiocyanate was calculated from a calibration graph.

\section{Plasma and urine specimens}

Venous blood samples from 15 healthy non-smokers and 5 smokers were drawn into $5 \mathrm{ml}$ Vacutainer tubes containing sodium heparin (Becton Dickinson, Rutherford, NJ). Plasma was separated by centrifugation at $2500 \mathrm{~g}$ for 10 minutes and stored at $-20^{\circ} \mathrm{C}$ until analysis. Untimed urinary samples were obtained from 15 healthy non-smokers and 5 smokers. Thiocyanate in plasma and urine samples are stable for at least six months when stored at $-20^{\circ} \mathrm{C}(18)$.

\section{Results}

Clean-up of plasma and urine

In the earlier method (18) urine and plasma samples were diluted with sodium hydroxide, $0.1 \mathrm{~mol} / 1$, for dissociation of thiocyanate from albumin (28). With this procedure we occasionally found recoveries of added thiocyanate as low as $83 \%$. With a stronger alkaline solution, $1.0 \mathrm{~mol} / 1$, we now obtained quantitative recoveries both with urine and plasma samples.

\section{Chlorination}

Sodium hypochlorite in water solution is in a dynamic equilibrium with chlorine as follows:

$$
\mathrm{ClO}^{-}+\mathrm{Cl}^{-}+\mathrm{H}_{2} \mathrm{O} \leftrightarrow \mathrm{Cl}_{2}+2 \mathrm{OH}^{-}
$$

The chlorine then reacts with thiocyanate:

$$
\begin{aligned}
4 \mathrm{Cl}_{2}+\mathrm{SCN}^{-}+4 \mathrm{H}_{2} \mathrm{O} \rightarrow & \mathrm{CNCl}+8 \mathrm{H}^{+} \\
& +7 \mathrm{Cl}^{-}+\mathrm{SO}_{4}^{2-}
\end{aligned}
$$

It is advantageous if both the chlorinating reaction, the formation of glutaconic aldehyde derivative, and the colour development can be performed at the same $\mathrm{pH}$ and in sequence.

The chlorination of thiocyanate was therefore investigated together with isonicotinic acid and 1,3-dimethylbarbituric acid as colour reagents. The $\mathrm{pH}$ optimum of the reaction was broad (fig. 2), and the addition of 0.2 $\mathrm{ml}$ of $0.35 \mathrm{~mol} / \mathrm{l}$ acetic acid to a $4.0-\mathrm{ml}$ effluent gave a $\mathrm{pH}$ of 4.0. At this $\mathrm{pH}$ the reaction between thiocyanate and hypochlorite was practically instantaneous and the absorbance was constant within the tested range of 10120 seconds.

\section{Amount of colour reagent}

When we varied the volume of colour reagent in the assay from 0.1 to $1.0 \mathrm{ml}$ the absorbance increased up to the addition of $0.9 \mathrm{ml}$ reagent (fig. 3), but only a slight increase in absorbance was observed after addition of $0.5 \mathrm{ml}$ reagent. Maximum absorbance was obtained within 10 min after the addition of the colour reagent (fig. 4). Then the colour slowly decreased with time.

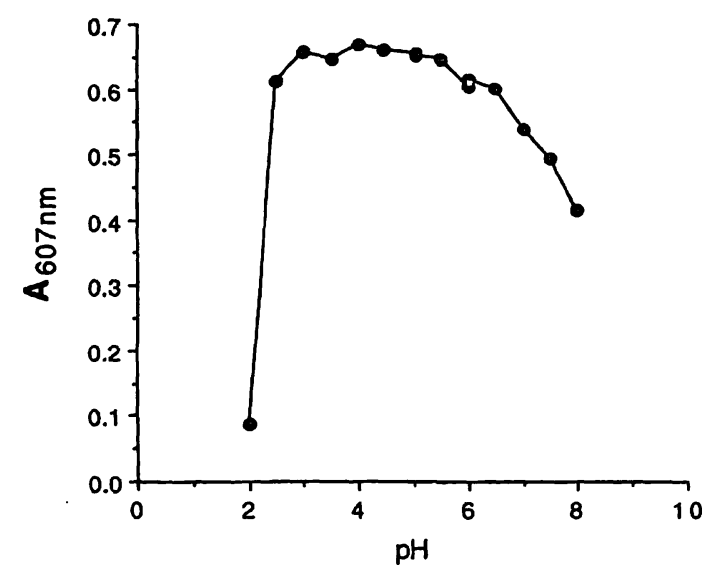

Fig. 2 Effect of $\mathrm{pH}$ on the formation of the dye

Tubes containing $4 \mathrm{ml}$ sodium perchlorate, $1.0 \mathrm{~mol} / 1,0.125 \mathrm{ml}$ ace-

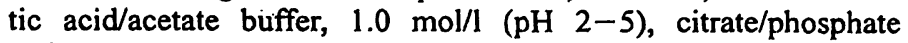

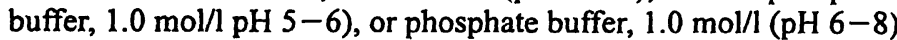
and $0.25 \mathrm{ml}$ of potassium thiocyanate, $100 \mu \mathrm{mol} / 1$, were added, $\mathrm{pH}$ was confirmed on a pH-meter. Colour development was performed as described.

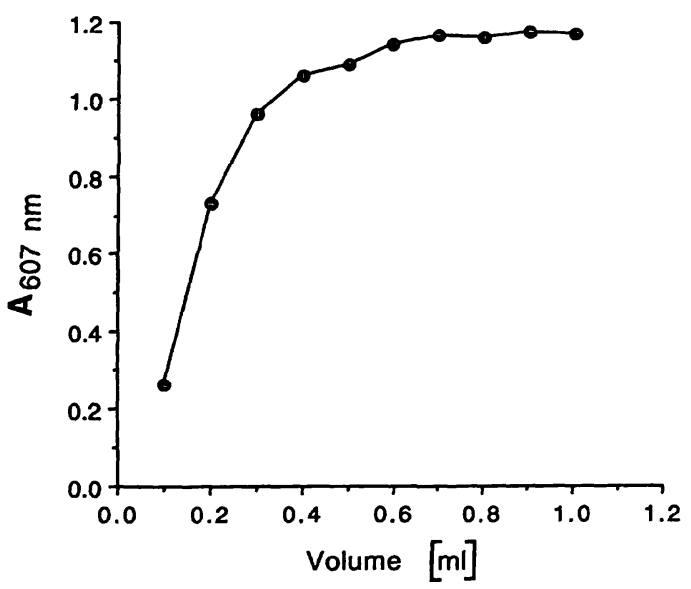

Fig. 3 Effect of amount of colour reagent on dye development Procedure as described in methods with exception of added water to a constant volume of $1.0 \mathrm{ml}$ for the colour reagent. $50 \mathrm{nmol}$ thiocyanate was added to assay.

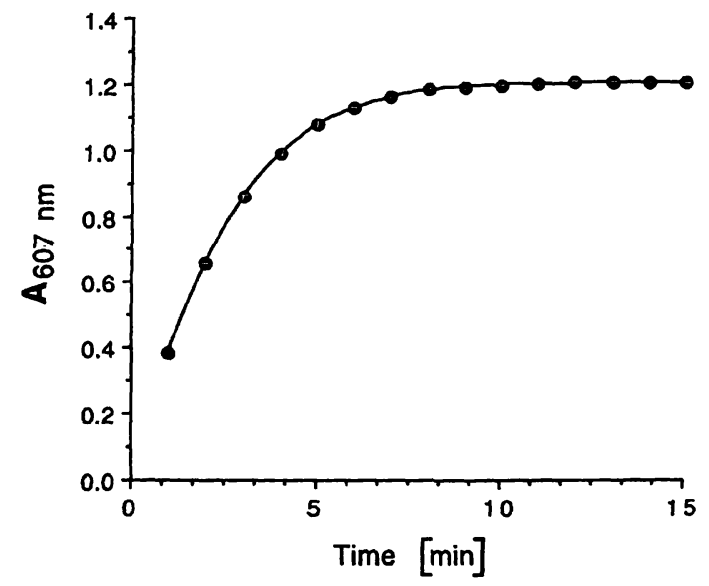

Fig. 4 Effect of time on colour development 
The absorption maximum of the dye formed in sodium perchlorate was at $607 \mathrm{~nm}$.

\section{Standard curve}

The standard curve was linear up to $500 \mu \mathrm{mol} / \mathrm{l}$ (fig. 5). However, a smaller amount of the sample should be taken to the assay if high thiocyanate concentrations are expected.

\section{Recovery, imprecision, and detection limit}

The absolute recovery of the method was tested by comparing the absorbance obtained from a standard solution of thiocyanate, $200 \mu \mathrm{mol} / \mathrm{l}$, passed through the column with that obtained after direct addition of thiocyanate to sodium perchlorate. In a triplicate experiment the absolute recoveries were $101.9,99.6$ and $98.9 \%$ respectively.

Analytical recovery of thiocyanate, $50 \mu \mathrm{mol} / \mathrm{l}$, added in duplicate experiments to plasma samples with thiocyanate concentrations of 35.0 and $71.5 \mu \mathrm{mol} / 1$ respectively, were $96,99 \%$ and $97,97 \%$ respectively. Thiocyanate, $50.0 \mu \mathrm{mol} / \mathrm{l}$, added in duplicate to urine samples containing 49.0 and $96.3 \mu \mathrm{mol} / \mathrm{l}$ respectively of thiocyanate gave recoveries of $97,98 \%$ and $102,104 \%$ respectively. The within-day imprecision of the method was evaluated by analysis of ten aliquots of a plasma sample and of 10 aliquots of a urine sample. The results obtained (mean and SD) with plasma was $107.1 \pm 1.17 \mu \mathrm{mol} / \mathrm{l}(\mathrm{CV}$ $1.1 \%$ ) and with urine $167.4 \pm 1.15 \mu \mathrm{mol} / \mathrm{l}$ (CV 0.69). The long-term imprecision of the method was determined by analysis of aliquots of a urine sample stored at $-20^{\circ} \mathrm{C}$ on 10 different days for a period of 65 days. The total mean was $117.9 \mu \mathrm{mol} / \mathrm{l}$, SD $1.16 \mu \mathrm{mol} / \mathrm{l}$, and CV $0.98 \%$. The detection limit was $0.93 \mu \mathrm{mol} / 1$ when

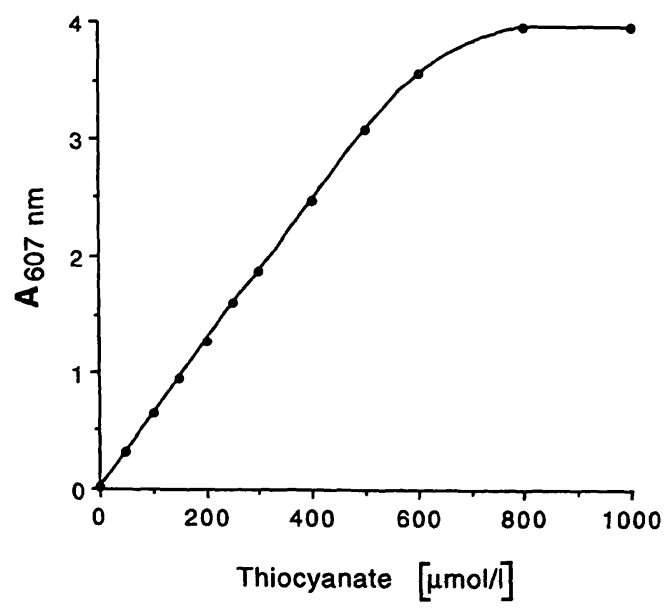

Fig. 5 Standard curve

To the alkaline application solution $25-500 \mathrm{nmol}$ potassium thiocyanate was added. Regression line from the added standard concentrations $0-500 \mu \mathrm{mol} / \mathrm{l}$ was $\mathrm{y}=0.030+0.006 x\left(r^{2}=1.00\right)$. defined as three times the SD value added to the mean of ten blank determinations.

\section{Colour reagent comparison}

To further validate the new colour reagent we analyzed 20 plasma and 20 urine samples from healthy non-smokers and smokers and compared the obtained values with the pyridine based reagent (18). The results obtained were in satisfactory agreement (fig. 6).

\section{Interference studies}

Compounds normally present in body fluids were tested for possible interference at concentrations encountered in urine. The following compounds neither gave any absorbance when added alone to the samples, nor affected the absorbance with thiocyanate, $100 \mu \mathrm{mol} / \mathrm{l}$, by more than $\pm 5 \%$ : sodium chloride, ammonium chloride, creatinine, urea, glycine and cystine. Some commonly prescribed drugs such as salicylic acid, $20 \mathrm{mmol} / 1$, ascorbic acid, $10 \mathrm{mmol} / \mathrm{l}$, and thiamine, $1 \mathrm{mmol} / \mathrm{l}$, also did not interfere. Isoniazid did not interfere when added to a concentration of $1 \mathrm{~g} / \mathrm{l}$ to a urinary sample.

Sodium nitroprusside had a strong negative interference. However, this interference could be eliminated by washing the ion-exchange column twice during the clean-up of the sample with $5 \mathrm{ml}$ of ammonium chloride, $4 \mathrm{~mol} / \mathrm{l}$, followed by $5 \mathrm{ml}$ of water. This procedure should include the calibrators since the absorbance decreased about $20 \%$.

Cloxacillin, $2 \mathrm{~g} / \mathrm{l}$, did not interfere when added to a urine sample. However, a positive interference was obtained when benzylpenicillin, $2 \mathrm{~g} / \mathrm{l}$, was added both to water blank and to five different urine samples. An apparent "thiocyanate" concentration of $25 \mu \mathrm{mol} / 1$ was observed in water samples and an additional "thiocyanate" concentration ranging from 13 to $24 \mu \mathrm{mol} / 1$ was found in the urine samples. For the urine samples the absorbance of benzylpenicillin was on molar basis only $0.25-$ $0.44 \%$ of that given by thiocyanate but administration of high doses of the interfering antibiotics may significantly affect the absorbance. Cephalothin interfered when added to water and urine samples on a molar basis half of that by benzylpenicillin. This interference could be eliminated in the same way as described for sodium nitroprusside.

Cyanide did not separate from thiocyanate in the chromatographic step, and it reacts quantitatively in the König reaction. The interference from cyanide, however, could be eliminated by washing the column twice with $5 \mathrm{ml}^{3}$ of hydrochloric acid, $1 \mathrm{~mol} / \mathrm{l}$, but the cyanide con- 


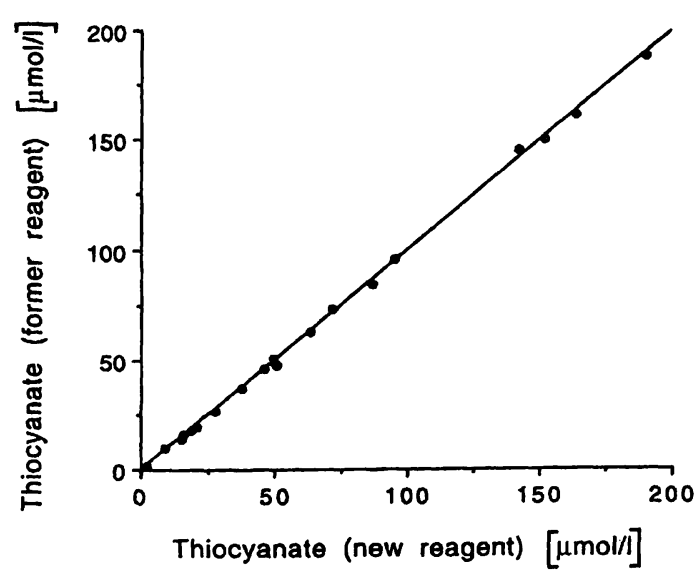

Fig. 6a Correlation between old and new reagent for determination of thiocyanate in serum

Regression line; $y=3.792+0.917 x\left(r^{2}=0.992\right)$.

centration in plasma and urine is normally $<0.1 \mu \mathrm{mol} / 1$ and this interference can therefore be neglected.

We recommend the additional column washings when the above mentioned interferences are expected in the samples.

\section{Discussion}

Several methods have been described for analysis of thiocyanate by use of König reactions $(9-26)$. However only a few of them $(14,18,19)$ have been developed for quantitative determinations of thiocyanate in plasma and urine. In the method of Boxer \& Richard (14) the samples were deproteinized and thiocyanate was oxidized to hydrogen cyanide by acid permanganate. By a stream of nitrogen the hydrogen cyanide was then transferred to a collection tube containing sodium hydroxide and determined by reacting with pyridine and 1-phenyl3-methyl-5-pyrazolone. An advantage of this procedure is the elimination of interfering compounds during aeration, but the procedure is cumbersome and requires special glass equipment, which makes the method applicable only to small series of samples.

In the methods developed earlier in our laboratory (18, 19) the sample was first purified by use of the affinity of selected ion exchangers for thiocyanate. This affinity is probably due to a chaotropic effect rather than an anion-exchange mechanism, and the thiocyanate could be eluted by the chaotropic perchlorate ion even at high $\mathrm{pH}$ when the resins are uncharged. As discussed in the second communication (19) the Lewatite MP 7080 resin first used in the clean-up (18) had to be replaced because the manufacturers modified the resin resulting in a reduced affinity for thiocyanate, and it could not be used in our clean-up procedure. Several other ion exchange resins were therefore tested for their ability to selectively

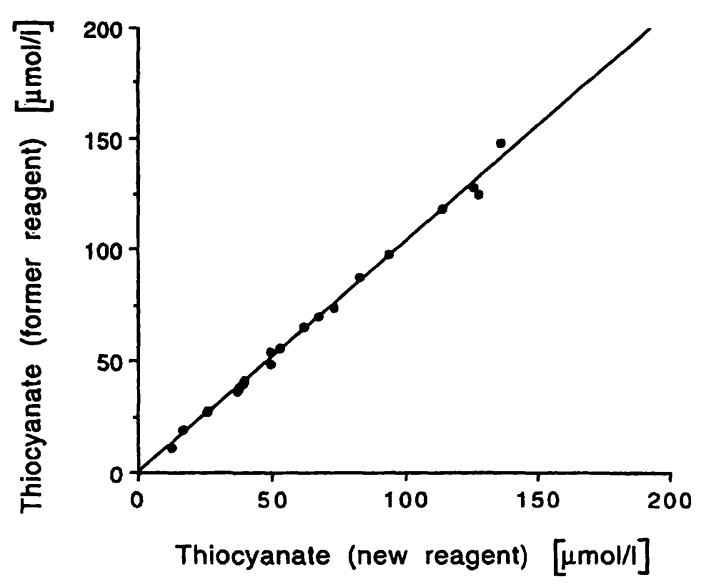

Fig. 6b Correlation between old and new reagent for determination of thiocyanate in urine

Regression line; $y=0.0911+1.037 x\left(r^{2}=0.995\right)$.

bind thiocyanate, and we found that some weakly basic anion-exchange resins with a polystyrene matrix had strong affinity to thiocyanate (19). Amberlyst A-21 (Röhm \& Haas Co., Philadelphia, USA) had a tertiary amine as functional group on a styrene-divinylbenzene copolymer matrix and was as effective as the original Lewatit MP 7080 resin in adsorbing thiocyanate (19). Unfortunately, Amberlyst A-21 is only available in particle size $0.05-0.1 \mathrm{~mm}$ (too small) and $0.3-1.0 \mathrm{~mm}$ (too large), and the larger particles therefore have to be ground in a laboratory mill to the size of $0.1-0.3 \mathrm{~mm}$ to obtain an optimal flow. Upon request the service of grinding and sieving can be offered from our laboratory. In separate experiments we also used the unground resin and reduced the flow by the use of a stop-cock. Although this procedure is a little trickier it gave the same results as grinding the resin.

The ion exchanger Amberlyst A-21 has a high affinity for the thiocyanate ion and efficient elution was obtained with $3.0 \mathrm{ml}$ of sodium perchlorate, $1 \mathrm{~mol} / \mathrm{l}$, from a column containing $1.0 \mathrm{ml}$ of Amberlyst A-21, demonstrating a more effective elution compared to Lewatite MP 7080. This made it possible to reduce the sample volume from $0.5 \mathrm{ml}$ to $0.25 \mathrm{ml}$ and the elution volume from 8.0 to $4.0 \mathrm{ml}$. We analysed two different plasma and urine samples with these reduced volumes and compared the result with the conventional procedure. The results obtained agreed excellently. Thus with the present ion exchanger we obtain results in accordance with that obtained with the formerly used ion exchanger. Since the earlier method (18) also gave excellent correlation with an oxidation method (14) we conclude that also the present method would give similar results.

Analytical methods should be evaluated by estimation of their precision and accuracy as well as by the costs 
and practicability of the method. As shown in results the imprecision of this method is quite satisfactory, and the recoveries were quantitative. Although satisfactory recovery is a requisite for an accurate method this is not enough for evaluation of accuracy. We therefore also investigated possible interference from other compounds. Several endogenous and exogenous compounds were tested and positive interferences were found with benzylpenicillin and cephalothin. These interferences are easily eliminated as described.

The present method is useful for detection of low endogenous concentrations of thiocyanate (detection limit 0.93 $\mu \mathrm{mol} / \mathrm{l}$ ) as well as the extremely high levels (up to 4.1 $\mathrm{mmol} / \mathrm{l}$ ) seen in some urine samples from populations in Africa depending on intake of cassava $(3,29)$. Cassava (manioc, Manihot utilissima) is a daily staple food for 400 million people (20) and contains the cyanogenic glucoside linamarin, which, if not properly processed before consumption, may cause cyanide intoxication. The normal human thiocyanate level (18) in serum is $42.5 \mu \mathrm{mol} / \mathrm{l}(\mathrm{SD} 17.1 \mu \mathrm{mol} / \mathrm{l}, \mathrm{n}=20$ ) and the urinary excretion of thiocyanate is $43.0 \mu \mathrm{mol} / 24 \mathrm{~h}$ (SD 22.1 $\mu \mathrm{mol} / 24 \mathrm{~h}, \mathrm{n}=20$ ). In an earlier paper we found the mean $\pm \mathrm{SD}$ serum concentration to be $48.7 \pm 30.6$ $\mu \mathrm{mol} / 1$ in non-smoking subjects $(\mathrm{n}=212)$, and smoking 1-9 cigarettes per day increased the concentration to $120 \pm 56.7 \mu \mathrm{mol} / \mathrm{l}$. With higher cigarette consumption (more than 20 cigarettes per day) the mean concentrations increased to $150 \pm 29.3 \mu \mathrm{mol} / 1$ (30). Measurement of thiocyanate levels after inhalation of fire smoke indi- cates exposure to hydrogen cyanide production from combustion of nitrogen containing materials such as plastics. The hypotensive drug sodium nitroprusside contains cyanide ( $44 \%$ of weight) which is metabolised to thiocyanate. Intake of thiocyanate-containing food such as milk, and intake of thiocyanogenic glucosides (cabbage, mustard) or cyanogenic glucosides (kernels, linseed, bamboo spurts) elevate the thiocyanate concentration in plasma and urine (31).

The present method affords several advantages over earlier methods $(14,18,19)$ for thiocyanate determination in biological materials such as plasma and urine, and we have also found the method suitable in the determination of saliva thiocyanate. As compared with our earlier method $(18,19)$ the important improvement with the present method is the replacement of the odorous pyridine with isonicotinic acid. This may be a particular advantage in the tropics in the monitoring of cyanide exposure from cassava. Facilities such as fume chambers may be missing in these developing countries, but the elimination of pyridine is also of great interest in wellequipped laboratories. The solid state of isonicotinic acid also facilitates transport and handling.

\section{Acknowledgements}

This work was supported by grants from The Swedish Medical Research Council (Project No. B95-13X-11211-01A), The Swedish Cancer Society (Project 2357-B94-09XCC), The Swedish Society of Medicine (Svenska Läkaresällskapets Forskningsfonder), The County Council of Östergötland, The Lions Foundation for Medical Research and by grant No. 9414 from Svenska Tobaks AB.

\section{References}

1. Pettigrew $A R$, Logan RW, Willocks J. Smoking in pregnancy - effects on birth weight and on cyanide and thiocyanate levels in mother and baby. $\mathrm{Br} \mathrm{J}$ Obstet Gynecol 1977; $84: 31-4$

2. Bowes PC. Smoke and toxicity hazards of plastics in fire. Ann Occup Hyg 1974; 17:143-57.

3. Cliff J, Lundquist $P$, Mårtensson J, Rosling H, Sörbo B. Association of high cyanide and low sulphur intake in cassavainduced spastic paraparesis. Lancet II 1985; 1211-3.

4. Langer P, Greer MA. Antithyroid substances and naturally occurring goitrogens. Basel: S Karger, 1977:135-7.

5. Pollay M, Stevens A, Davis C. Determinations of plasma-thiocyanate binding and the Donnan ratio under simulated physiological conditions. Anal Biochem 1966; 17:192-200.

6. Funderburk CF, Van Middlesworth L. The effect of thiocyanate concentration on thiocyanate distribution and excretion. Proc Soc Exper Biol Med 1971; 136:1249-52.

7. Lundquist $P$. Determination of cyanide and thiocyanate in humans [dissertation]. Linköping University Medical Dissertations 355, 1992. University Microfilms. Inc Publication A $253534,49-52$.

8. Schulz V. Clinical pharmacokinetics of nitroprusside, cyanide, thiosulphate and thiocyanate. Clin Pharmacokinetics 1984; 9:239-51

9. König W. Untersuchung aus dem organischen Laboratorium der Technischen Hochschule zu Dresden. LXIX. Über eine neue, vom Pyridin derivierende Klasse von Farbstoffen. J Prakt Chem 1904; 69:105-37.

10. Aldrige WN. A new method for the estimation of micro quantities of cyanide and thiocyanate. Analyst 1944; 69:262-5.

11. Aldridge WN. The estimation of micro quantities of cyanide and thiocyanate. Analyst 1945; 70:474-6.

12. Epstein J. Estimation of microquantities of cyanide. Anal Chem 1947; 19:272-4.

13. Asmus $E$, Garschagen $H$. Über die Verwendung der Barbitursäure für die photometrische Bestimmung von Cyanid und Rhodanid. Zeitschr Analyt Chem 1953; 138:414-22.

14. Boxer GE, Richards JC. Determination of thiocyanate in body fluids. Arch Biochem Biophys 1952; 39:292-300.

15. Somogyi M. A method for the preparation of blood filtrates for the determination of sugar. J Biol Chem 1930; 86:655-63.

16. Stöa KF. Studies on thiocyanate in serum. In: Second Medical Yearbook. Bergen: University of Bergen, Norway. 1957:13-49.

17. Nyström C, Sörbo B. The thiocyanate content in urine and blood from cases of toxemia of pregnancy. Scand J Clin Lab Invest 1957; 9:223-5.

18. Lundquist $\mathrm{P}$, Mårtensson J, Sörbo B, Öhman S. Method for determining thiocyanate in serum and urine. Clin Chem 1979; 25:678-81. 
19. Lundquist $\mathrm{P}$, Mårtensson J, Sörbo B, Öhman S. Absorption of thiocyanate by anion exchange resins and its analytical application. Clin Chem 1983; 29:403.

20. FAO. Roots, tubers, plantains and bananas in human nutrition. FAO Food and Nutrition Series, No 24. Rome: FAO, 1990.

21. Ishii K, Yamanishi $\mathrm{K}$. The spectrophotometric determination of cyanide ion with isonicotinic acid-pyrazolone. Jpn Anal 1973; 22:448.

22. Watanabe A, Ito I, Hirakoba A. Spectrophotometric determination of cyanide ion with isonicotinic acid-pyrazolone. Jpn Anal 1977; 26:505.

23. Nagashima S. Spectrophotometric determination of cyanide with sodium isonicotinate and sodium barbiturate. Analytica Chimica Acta 1978; 99:197-201.

24. Moderne Analysenmethoden. Darmstadt: Merck, 1983.

25. Essers AJA, Bosveld M, van der Grift, RM, Voragen AGJ. Studies on the quantification of specific cyanogens in cassava products and introduction of a new chromogen. J Sci Food Agric 1993; 63:287-96.

26. Meeussen JCL, Temminghoff EJM, Keizer MG, Novozamsky I. Spectrophotometric determination of total cyanide, iron cyanide complexes, free cyanide and thiocyanate in water by a continuous-flow system. Analyst 1989; 114:959-63.
27. Sörbo B, Öhman S. Determination of thiosulphate in urine. Scand J Clin Lab Invest 1978; 38:521-7.

28. Pande CS, Mc Menamy RH. Thiocyanate binding with modified bovine plasma albumins. Arch Biochem Biophys 1970; 136:260-7.

29. Cliff J, Lundquist P, Rosling H, Sörbo B, Wide L. Thyroid function in a cassava-eating population affected by epidemic spastic paraparesis. Acta Endocrinol (Copenh) 1986; 113:523-8.

30. Kågedal B, Mårtensson J, Sörbo B, Tibbling L. Serum levels of thiocyanate and thyroid hormones in smoking and nonsmoking subjects. Res Comm Subst of Abuse 1981;2:267-75.

31. Wood JL. Biochemistry. In: Newman AA, editor. Chemistry and biochemistry of thiocyanic acid and its derivatives. London, New York, San Francisco: Academic Press, 1975:157221.

Per Lundquist

SKL - National Laboratory of Forensic Sciences

Olaus Magnus väg

S-581 94 Linköping

Sweden 
